\title{
A Study of Temporomandibular Joint Sounds Part 2. Acoustic Characteristics of Joint Sounds
}

\author{
Mitsuru Motoyoshi, Yukiyoshi Matsumoto, Mayuko Ohnuma, Masae Arimoto, \\ Katsuaki Takahashi and Shinkichi Namura
}

(Received 24 August and accepted 21 December 1994)

Key words: TMJ sound, acoustic analysis, opening click, closing click

\begin{abstract}
In an attempt to gain a better understanding of temporomandibular joint (TMJ) sounds, we recorded joint sounds from 14 non-orthodontically treated dental students, analyzed the acoustic characteristics of the TMJ sounds, and correlated the sound characteristics with axiographic features, morphologic observations of X-ray images and clinical history. The group with a low peak frequency $(<500 \mathrm{~Hz})$ of the opening click had a shorter history of subjective joint sound, a longer distance between the opening and closing curves, and a low rate of TMJ transformation. For the closing click, the history of subjective joint sounds tended to be longer when the duration of the wave was short.

Acoustic analysis of TMJ sounds could be an aid to the differential diagnosis of temporomandibular disorders, although it is difficult to deduce the clinical history and internal deformities of the TMJ based solely on acoustic characteristics.
\end{abstract}

\section{Introduction}

It is generally considered that temporomandibular joint (TMJ) sounds should be a sign of stomatognathic dysfunction. Epidemiologic studies have suggested that TMJ sounds indicate irregularities and adhesions on the articular surfaces and disk displacement with reduction ${ }^{[1,2]}$. In our previous study ${ }^{[3,4]}$, the incidence of TMJ sound, and the relationship between the presence of sound and the prevalence of disc displacement were investigated in an attempt to find the causes of TMJ sounds. Early opening sounds may be related to irregularities at the lateral pole of the condyle owing to tension from the lateral ligament and/or stretching of the ligament. Late opening sounds may follow the slight condylar slips over the anterior ridge of the disc close to the maximum mouth opening position, and this may be associated with a decrease of synovia. In this study, we concentrated on the acoustic characteristics of TMJ sounds, and separated the signals into their spectral components. The time frequency distributions were also analyzed in order to accumulate some diagnostic information on TMJ disorders.

\section{Materials and Methods}

Non-orthodontically treated dental students at Nihon University School of Dentistry who complained of TMJ sounds were examined for the presence of clicking using a stethoscope. Fifteen joints producing sounds during jaw opening and 14 joints producing sounds during closing movement were detected among 14 students (Table 1). These joint sounds were then recorded on a DAT (SONY TCD-D10) using a microphone (TOEI MM80S) with resin caps made for fitting to the external ear (Fig.1). An analog/digital converter with a $25 \mu \mathrm{s}$ conversion time and a 12-bit resolution was used for digitization of the recorded signal, and the duration of the wave was measured. The digital wave was separated into its spectral components by the fast Fourier transform (FFT) after 7-point smoothing, and the peak frequency and limits of maximum

本吉 満、松本幸良、大沼麻由子、有本方恵、高橋勝昭、納村晉吉

Department of Orthodontics, Nihon University School of Dentistry

To whom all correspondence should be addressed: Dr. Mitsuru Motoyoshi, Department of Orthodontics, Nihon University School of Dentistry, 1-8-13 Kanda-Surugadai, Chiyoda-ku, Tokyo 101, JAPAN 
frequency of the power spectrum were measured. Thereafter the time frequency distribution of the sound was calculated and displayed as a sonogram. Joint movements were traced by a computer-aided axiograph (SAM CADIAX). On the axiographic tracings of the hinge-axis point, maximal distances between the opening and closing curves were measured (Fig.2) and the bulge suspected to indicate the presence of disarrangement was investigated (Fig.3). Information about restricted condylar movement and the history of subjective joint sounds was obtained from an interview questionnaire. Presence of transformation of the condyle was diagnosed using X-ray images for each subject.

Table 1 Distribution of TMJ sounds

\begin{tabular}{lcc}
\hline & \multicolumn{2}{c}{ TMJ sounds } \\
\cline { 2 - 3 } & During opening movement & During closing movement \\
\hline Right & 8 & 8 \\
Left & 7 & 6 \\
TOTAL & 15 & 14 \\
Male & 8 & 6 \\
Female & 2 & 1 \\
TOTAL & 10 & 7 \\
Age (mean) & & $23.6 \mathrm{y}$ \\
\hline
\end{tabular}

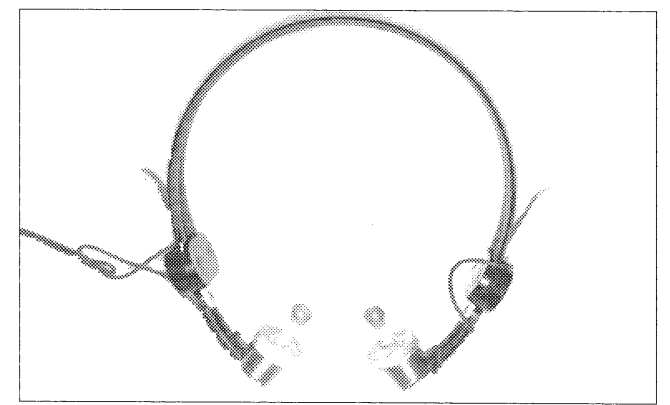

Fig. 1 A pair of microphones with resin caps for fitting to the external ears

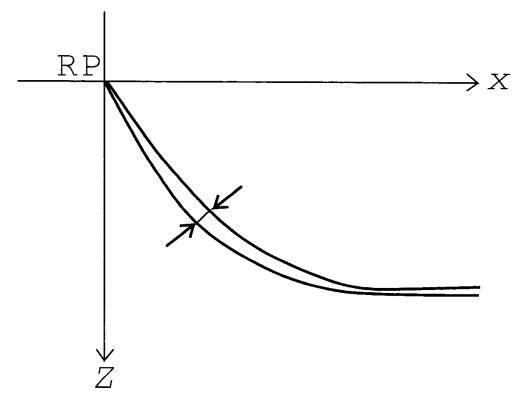

Fig. 2 A method of measuring maximum distance between the opening and closing curves of the axiographic tracing

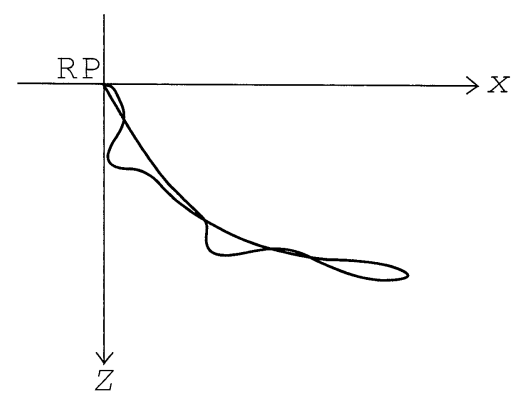

Fig. 3 The bulge suggestive of disarrangement on the axiographic tracing 


\section{Results}

The results of acoustic analysis of joint sounds during opening along with diagnostic information are shown in Tables 2 through 4 . With regard to the duration of digital waves, no significant difference was observed (Table 2). The subjects were divided into two groups by the peak frequency at $500 \mathrm{~Hz}$. There were significant differences in the maximal distance between the opening and closing axiographic curves, the history of subjective joint sounds and the transformation of the condyle (Table 3). We then sorted the subjects according to the limits of maximal frequency of the power spectrum. No significant difference between the high-frequency group $(\geqq 500 \mathrm{~Hz})$ and the low-frequency group $(<500 \mathrm{~Hz})$ was observed (Table 4).

For joint sounds that occurred during the closing movement, a significant difference in the history of subjective joint sounds was observed between the groups with a wave duration of less than and more than $40 \mathrm{~s}$ (Table 5). There were no significant differences in the peak frequency and the limits of maximal frequency of the power spectrum (Tables 6 and 7).

Figure 4 shows a scattergram of the peak frequencies of the opening click in 15 joints, which were divisible into two groups, one around $70 \mathrm{~Hz}(\mathrm{~A})$ and the other around $800 \mathrm{~Hz}(\mathrm{~B})$. The time frequency distributions for each subject were calculated and displayed as the sonogram. In typical contour-plots (sonogram) of TMJ sounds, varied features were observed. As the frequency component changes were observed with time in group A, high-frequency components were synchronized with the maximal amplitude of the wave, and low-frequency components were carried to the latter half of the wave (Fig.5). The sonogram for group B (Fig.6) showed an obscure picture indicating no significant features of temporal change in the frequency component.

Table 2 Association between duration of the wave and diagnostic information

- Opening click -

\begin{tabular}{|c|c|c|c|c|}
\hline & \multicolumn{3}{|c|}{ Duration of the wave } & \multirow[b]{2}{*}{ sig.* } \\
\hline & & $<40 \mu \mathrm{s}$ & $\geqq 40 \mu \mathrm{s}$ & \\
\hline Maximal distance between & mean & 1.1 & 1.3 & - \\
\hline opening curve \& closing curve & S.D. & 0.5 & 0.5 & \\
\hline The bulge on axiographic tracing & & $29 \%$ & $63 \%$ & - \\
\hline History of subjective joint & mean & 7.3 & 5.4 & - \\
\hline sounds & S.D. & 6.3 & 5.0 & \\
\hline $\begin{array}{l}\text { Existence of restricted condylar } \\
\text { movement in clinical history }\end{array}$ & & $14 \%$ & $63 \%$ & - \\
\hline Transformation of the condyle & & $57 \%$ & $13 \%$ & - \\
\hline
\end{tabular}

* Student's t test 
Table 3 Association between peak frequency and diagnostic information

- Opening click -

\begin{tabular}{|c|c|c|c|c|}
\hline & \multicolumn{4}{|c|}{ Peak frequency } \\
\hline & & $\geqq 500 \mathrm{~Hz}$ & $<500 \mathrm{~Hz}$ & sig.* \\
\hline Maximal distance between & mean & 0.8 & 1.4 & $5 \%$ \\
\hline opening curve \& closing curve & S.D. & 0.3 & 0.5 & \\
\hline The bulge on axiographic tracing & & $0 \%$ & $64 \%$ & - \\
\hline History of subjective joint & mean & 10.8 & 4.6 & $5 \%$ \\
\hline sounds & S.D. & 6.1 & 4.6 & \\
\hline $\begin{array}{l}\text { Existence of restricted condylar } \\
\text { movement in clinical history }\end{array}$ & & $0 \%$ & $55 \%$ & - \\
\hline Transformation of the condyle & & $100 \%$ & $9 \%$ & $1 \%$ \\
\hline
\end{tabular}

* Student's t test

Table 4 Association between limits of maximum frequency and diagnostic information

- Opening click -

\begin{tabular}{|c|c|c|c|c|}
\hline & \multicolumn{4}{|c|}{ Limits of maximum frequency } \\
\hline & & $\geqq 500 \mathrm{~Hz}$ & $<500 \mathrm{~Hz}$ & sig.* \\
\hline Maximal distance between & mean & 1.1 & 1.3 & - \\
\hline opening curve \& closing curve & S.D. & 0.5 & 0.4 & \\
\hline The bulge on axiographic tracing & & $29 \%$ & $63 \%$ & - \\
\hline History of subjective joint & mean & 7.0 & 5.6 & - \\
\hline sounds & S.D. & 6.6 & 4.8 & \\
\hline $\begin{array}{l}\text { Existence of restricted condylar } \\
\text { movement in clinical history }\end{array}$ & & $14 \%$ & $63 \%$ & - \\
\hline Transformation of the condyle & & $57 \%$ & $13 \%$ & - \\
\hline
\end{tabular}

* Student's t test 
Table 5 Association between duration of the wave and diagnostic information

- Closing click -

\begin{tabular}{|c|c|c|c|c|}
\hline & \multicolumn{4}{|c|}{ Duration of the wave } \\
\hline & & $<40 \mu \mathrm{s}$ & $\geqq 40 \mu \mathrm{s}$ & sig.* \\
\hline Maximal distance between & mean & 1.1 & 1.4 & - \\
\hline opening curve \& closing curve & S.D. & 0.6 & 0.5 & \\
\hline The bulge on axiographic tracing & & $25 \%$ & $50 \%$ & - \\
\hline History of subjective joint & mean & 7.5 & 1.0 & $5 \%$ \\
\hline sounds & S.D. & 7.5 & 1.0 & \\
\hline $\begin{array}{l}\text { Existence of restricted condylar } \\
\text { movement in clinical history }\end{array}$ & & $25 \%$ & $0 \%$ & - \\
\hline Transformation of the condyle & & $25 \%$ & $0 \%$ & - \\
\hline
\end{tabular}

* Student's t test

Table 6 Association between peak frequency and diagnostic information

- Closing click -

\begin{tabular}{|c|c|c|c|c|}
\hline & & \multicolumn{3}{|c|}{ Peak frequency } \\
\hline & & $\geqq 500 \mathrm{~Hz}$ & $<500 \mathrm{~Hz}$ & sig.* \\
\hline \multirow{2}{*}{$\begin{array}{l}\text { Maximal distance between } \\
\text { opening curve \& closing curve }\end{array}$} & mean & 0.7 & 1.3 & \multirow[t]{2}{*}{-} \\
\hline & S.D. & 0.4 & 0.6 & \\
\hline The bulge on axiographic tracing & & $0 \%$ & $42 \%$ & - \\
\hline \multirow{2}{*}{$\begin{array}{l}\text { History of subjective joint } \\
\text { sounds }\end{array}$} & mean & 4.0 & 4.8 & \multirow[t]{2}{*}{-} \\
\hline & S.D. & 0.1 & 7.0 & \\
\hline $\begin{array}{l}\text { Existence of restricted condylar } \\
\text { movement in clinical history }\end{array}$ & & $0 \%$ & $17 \%$ & - \\
\hline Transformation of the condyle & & $0 \%$ & $17 \%$ & - \\
\hline
\end{tabular}

* Student's t test 
Table 7 Association between limits of maximum frequency and diagnostic information

- Closing click -

\begin{tabular}{|c|c|c|c|c|}
\hline & \multicolumn{4}{|c|}{ Limits of maximum frequency } \\
\hline & & $\geqq 500 \mathrm{~Hz}$ & $<500 \mathrm{~Hz}$ & sig.* \\
\hline Maximal distance between & mean & 1.0 & 1.3 & - \\
\hline opening curve $\&$ closing curve & S.D. & 0.6 & 0.5 & \\
\hline The bulge on axiographic tracing & & $0 \%$ & $50 \%$ & - \\
\hline History of subjective joint & mean & 8.5 & 3.2 & - \\
\hline sounds & S.D. & 6.7 & 5.8 & \\
\hline $\begin{array}{l}\text { Existence of restricted condylar } \\
\text { movement in clinical history }\end{array}$ & & $25 \%$ & $10 \%$ & - \\
\hline Transformation of the condyle & & $25 \%$ & $10 \%$ & - \\
\hline
\end{tabular}

* Student's t test

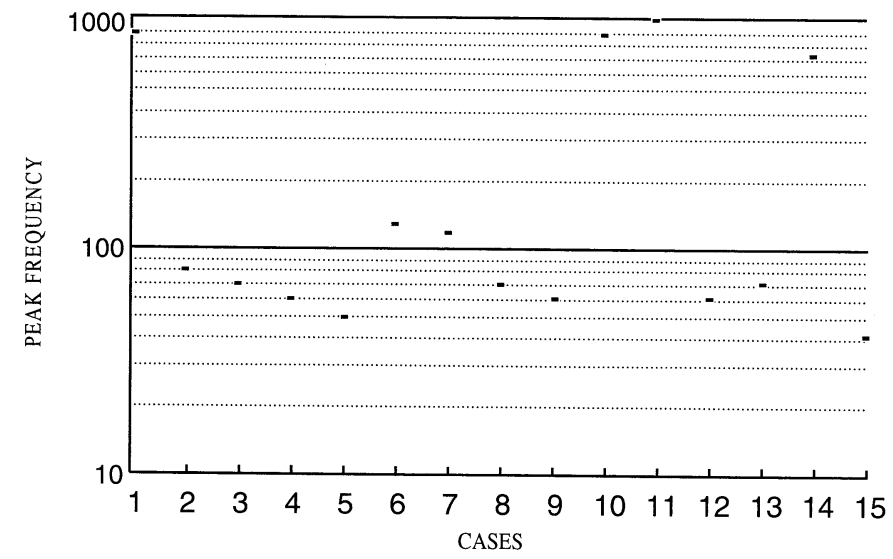

Fig. 4 Scattergram of peak frequency of the opening click

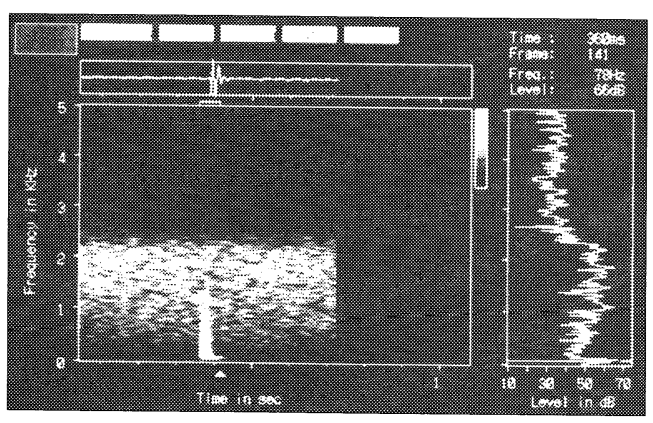

Fig. 5 Time frequency distribution from group A joint with clicking during opening

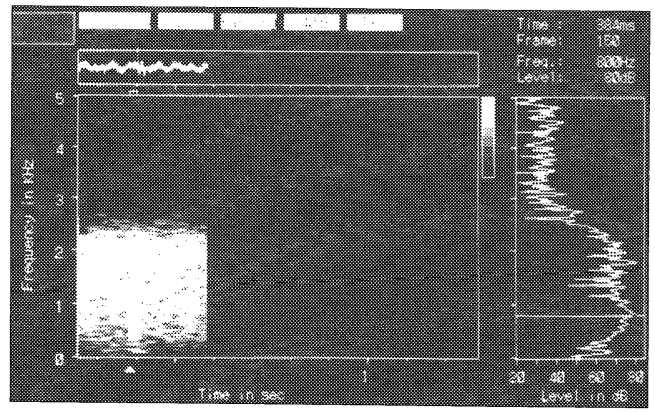

Fig. 6 Time frequency distribution from group B joint with clicking during opening 


\section{Discussion}

In order to develop a diagnostic method for TMJ disorders, it is important to differentiate between sounds that indicate pathology and those that do not. A number of studies have attempted to characterize certain variations in TMJ sounds, and the analog forms of TMJ sounds have been recorded by many researchers ${ }^{[5-9]}$. However, it is difficult to interpret variations in these analog forms. In order to analyze TMJ sounds quantitatively, it is necessary to separate the signals into their spectral components. Recently, many researchers ${ }^{[10-16]}$ have carried out acoustic analysis of joint sounds, but a clear understanding of its diagnostic value has not yet been obtained.

When our present subjects were divided into two groups at a boundary peak frequency of $500 \mathrm{~Hz}$, significant differences were observed in the maximal distance between the opening and closing curves, the history of subjective joint sounds and the incidence of condylar transformation. The group with a low peak frequency $(<500 \mathrm{~Hz})$ showed a larger maximal distance, a shorter history and a lower incidence of transformation than the group with a high peak frequency $(\geqq 500 \mathrm{~Hz}$ ). TMJ sounds due to slipping of articular discs were recognizable by the presence of irregular jaw movement, a short history and lack of condylar transformation. If the peak wave frequency of the TMJ sound was low, then slipping of the articular discs might be suspected. Conversely, a long history, with the presence of condylar transformation due to injury of the articular disks or retrodiscal ligaments might be associated with a high peak frequency.

Only in the duration of the wave during jaw closing was a significant difference observed; the group with a duration of less than $40 \mu$ s showed a longer history of subjective TMJ sounds than the group with a duration of more than $40 \mu \mathrm{s}$. It is considered that the amplitude of signals during closing sounds can be smaller than those during opening sounds, and thus it is difficult to extract pure signals of small sounds from the signal to noise ratio.

The distribution of the peak values for opening sounds allowed the subjects to be divided into two groups; an approximately $70 \mathrm{~Hz}$ group (A) and an $800 \mathrm{~Hz}$ group (B)(Fig.4). Group A had a shorter history and a lower incidence of condylar transformation than group $B$. Therefore, measurement of the peak frequency of TMJ sounds might help to clarify their cause. If the sounds are caused by slipping of the articular discs during opening movement, the frequency peak would be around $70 \mathrm{~Hz}$, whereas if the sounds are due to perforation of the discs or retrodiscal pad, the frequency peak would be approximately $800 \mathrm{~Hz}$. Considering the sonogram of TMJ sounds in group A, high-frequency components were synchronized with the maximal amplitude of the wave. However, low-frequency components left their traces in the latter half of the wave. This feature of the time frequency distribution may be important for finding the characteristic sounds resulting from slippage of the articular discs. The sonogram for group B had no significant feature related to changes in the frequency component with time.

\section{Conclusions}

1. Acoustic analysis of joint sounds during opening

When the present subjects were divided into two groups according to the peak frequency at $500 \mathrm{~Hz}$, there were significant differences in the maximal distance between the opening and closing axiographic curves, the history of subjectives joint sounds and the transformation of the condyle. No significant difference was observed in other measurements.

2. Acoustic analysis of joint sounds during closing

A significant difference was observed only between the groups with a wave duration of more than or less than $40 \mu \mathrm{s}$ and in the history of joint sounds.

3. The scattergram of the peak frequencies was divisible into two groups; one of approximately $70 \mathrm{~Hz}$ (A) and one of about $800 \mathrm{~Hz}$ (B), and the time frequency of distribution was calculated and displayed on a sonogram. The results suggest that the time frequency distributions may be important for finding the characteristic sounds of TMJ dysfunction. 


\section{References}

[ 1 ] Westesson, P.-L., Bronstein, S.L. and Liedber, G.J.L.: Internal derangement of the temporomandibular joint; Morphologic description with correlation to joint function, Oral Surg. Oral Med. Pathol., 59, 323-331, 1985

[2] Widmalm, S., Westesson, P.-L., Brooks, S.L., Hatala, M.P. and Paesani, D.: Temporomandibular joint sounds: Correlation to joint structure in fresh autopsy specimens, Am. J. Orthod. Dentofac. Orthop., 101, 60-69, 1992

[3 ] Motoyoshi, M., Inoue, K., Kiuchi, K., Ohya, M., Nakajima, A., Aramoto, T. and Namura, S.: Relationships of condylar path angle with malocclusion and temporomandibular joint disturbances, $J$. Nihon Univ. Sch. Dent., 35, 43-48, 1993

[4] Motoyoshi, M., Ohya, M., Hasegawa, M. and Namura, S.: A study of temporomandibular joint sounds; Part 1. Relationship with articular disc displacements, J. Nihon Univ. Sch. Dent., 36, 48-51, 1991

[5] Runge, M.E., Sadowsky, C., Sakols, E. and Begole, E.A.: The relationship between temporomandibular joint sounds and malocclusion, Am. J. Orthod. Dentofac. Orthop., 96, 36-42, 1989

[6] Willigen, J.V.: The sagittal condylar movements of the clicking temporomandibular joint, J. Oral Rehab., 6, 167-175, 1979

[ 7 ] Rohlin, M., Westesson, P.-L. and Eriksson, L.: The correlation of temporomandibular joint sounds with joint morphology in fifty-five autopsy specimens, J. Oral Maxillofac. Surg., 43, 194-200, 1985

[ 8 ] Eriksson, L., Westesson, P.-L. and Rohlin, M.: Temporomandibular joint sounds in patients with disc displacement, Int. J. Oral Surg., 14, 428-436, 1985

[ 9 ] Toolson, G.A. and Sadowsky, C.: An evaluation of the relationship between temporomandibular joint sounds and mandibular movements, J. Craniomand. Disorders, 5, 187-196, 1991

[10] Gallo, L.M., Airoldi, R., Ernst, B. and Palla, S.: Power spectral analysis of temporomandibular joint sounds in asymptomatic subjects, J. Dent. Res., 72, 871-875, 1993

[11] Ouellette, P.L.: Temporomandibular joint sound prints; Electronic auscultation and sonographic and audiospectral analysis of the temporomandibular joint, J. Am. Dent. Assoc., 89, 623, 1974

[12] Yashiro, K., Narita, N., Matsumoto, T. and Ikeda, S.: Determining the quantity of temporomandibular joint sounds; Part 1. Systematizing of acoustic analysis on clicking, Nihon Univ. J. Oral Science, 16, 372-378, 1990 (in Japanese)

[13] Haga, K., Shiga, H. and Kobayashi, Y.: A clinical study of temporomandibular joint sounds; Part 2. The standard of the measurements, Odontology, 76, 452-453, 1988 (in Japanese)

[14] Akiyama, H., Shiga, H., Satoh, T. and Kobayashi, Y.: A clinical study of the temporomandibular joint; Part 1. A method of analysis, Odontology, 76, 218-219, 1988 (in Japanese)

[15] Suzuki, H.: An acoustic study of temporomandibular joint sounds, J. Stomatol. Soc. Japan, 57, 612630, 1990 (in Japanese)

[16] Ishioka, Y., Kobayashi, Y., Hasegawa, N., Kono, S. and Hayashi, T.: The Basis and the Application of Mandible-oral Functional Analysis; How to use MEI Instruments Clinically in a Better Way, 116-126, 256-259, 1st ed., Dental Diamond Co., 1991 (in Japanese) 